\title{
COVID-19 a nivel local: SEIR+ un modelo para proyectar escenarios epidemiológicos y demandas hacia el sistema sanitario*
}

\author{
Alejandro Danón ${ }^{\dagger}$, Andrés S. Mena, Andrés Ramasco§
}

\begin{abstract}
Resumen
Este trabajo presenta un modelo capaz de describir y proyectar la evolución del COVID-19 a nivel local. Para ello, diseñamos, programamos, y calibramos un modelo epidemiológico "SEIR plus" que además de los cuatro estados principales del modelo SEIR clásico, describe la trayectoria de enfermos severos y críticos, estados esenciales para la planificación del sistema de salud. Además, sumamos particularidades locales, como ser la curva etaria de la población y medidas de mitigación que impacten en el factor reproductivo. Asimismo, nuestro modelo es estocástico debido a la incorporación de incertidumbre en variables claves asociadas al virus y de difícil proyección para el hacedor de políticas. El modelo muestra un buen ajuste adentro y afuera de la muestra en su aplicación a Ciudad de Buenos Aires y Tucumán, Argentina. Finalmente, mostramos su aplicación para Tucumán, proyectando un escenario epidemiológico factible, y las demandas del sistema sanitario.
\end{abstract}

Palabras claves: COVID, pronóstico SEIR, demanda sanitaria

\begin{abstract}
This article presents a model able to describe and forecast the evolution of Covid-19 at the local level. This involves the design, programming and calibration of an epidemiological model that, in addition to the four states of a SEIR model, describes the path of severe and critical patients, fundamental states in order to plan the health system. Our model embeds local characteristics, such as the age composition of the population and the effect of mitigation measures on the reproductive factor. Likewise, our model is stochastic due to the incorporation of uncertainty in key variables associated with the virus and of difficult projection for the policy maker. Besides, we show the goodness of fit inside and outside the sample for Tucumán and Ciudad de Buenos Aires, Argentina. Finally, we show its application at the local level, forecasting a likely epidemiological scenario, and demands to the health system for Tucumán, Argentina.
\end{abstract}

Keywords: COVID, SEIR forecasting, healthcare system demand

JEL: C60, I10, C00

DOI: https://doi.org/10.46553/ensayos.3.3.2021.p1-24

Fecha de recepción: 23/04/2021; Fecha de aceptación: 30/07/2021

\footnotetext{
* Agradecemos las contribuciones de la Arq. Luisina Chiarello en la elaboración y diseño de imágenes, y de los doctores Agustín Reyes Cano y Benjamín Muedra en la elaboración de la base de datos de casos confirmados por provincia. También al equipo médico del Sanatorio 9 de Julio quienes organizaron una reunión de discusión donde recibimos valiosos comentarios, y a todos aquellos que lo leyeron y realizaron aportes. El resto de los errores son todos nuestros.

+ Universidad Nacional de Tucumán y BICE. Email: ale.m.danon@gmail.com

* Universidad Nacional de Tucumán y CONICET. Email: asmena@face.unt.edu.ar

§ Universidad Nacional de Tucumán. Email: ramascoandres@gmail.com
} 


\section{Introducción}

Durante diciembre de 2019, una serie de casos de neumonía, luego conocido como COVID-19 (coronavirus disease 2019), fueron reportados en la ciudad de Wuhan (China) y el 9 de enero se identificó la primera muerte de una paciente diagnosticada con esta enfermedad. El 30 de enero, luego de que se registraran infectados que no habían visitado China (en Alemania, Estados Unidos, Japón, y Vietnam), la Organización Mundial de la Salud (OMS) declaró la "Emergencia de Salud Pública Internacional" y la definió como pandemia. En junio, habiendo superado los 10 millones de infectados y 500 mil fallecidos (comprobados), esta pandemia ya se compara con la Gran Gripe Española que azotó al mundo a principios del Siglo XX, la cual contagió al 20\% de la población y mató al $2 \%$.

En Argentina, hasta agosto de 2020, se registraban más de 200 mil infectados confirmados y casi 4.000 fallecidos. A nivel subnacional, se observa una evolución de la epidemia sumamente diversa en la enfermedad, mostrando un desarrollo más avanzado en el Área Metropolitana de Buenos Aires. En Tucumán esta cifra supera los 300 infectados y 5 muertes. Por supuesto, el número de confirmados sigue por detrás al número de infectados como resultado de que existe un porcentaje de pacientes asintomáticos y capacidades de testeo restringidas y rezagadas.

Esta situación presenta un desafío tanto para el sistema sanitario como para el sistema económico y social, los cuales deben ser capaces de sobrevivir al propio virus y a las medidas de mitigación que los agentes y gobiernos adoptan. En ese sentido, para mejorar las decisiones de los individuos y hacedores de políticas es clave tanto el acceso a información, como los modelos para interpretarla. El objetivo de este trabajo es brindar una herramienta, adaptada a nivel local, para comprender y trazar distintos escenarios para las demandas hacia el sistema sanitario. En particular, exponer posibles trayectorias acerca del número de infectados, hospitalizados y cuidados intensivos, y las demandas derivadas de ello (ej. médicos, respiradores, terapistas), además de cuándo podemos esperar que esto suceda.

Para nuestras estimaciones partimos del modelo canónico para la predicción de las epidemias, conocido por sus siglas SEIR, correspondiente a los cuatro compartimentos o estados de la población: Susceptible; Expuestos; Infectados y Recuperados o "Removidos" (Atkeson (2020a), Berger et al. (2020), Guan et al. (2020), Wu et al. $(2020))^{1}$. A estos grupos, sumamos compartimentos necesarios para la planificación del sistema sanitario: enfermos severos (hospitalizaciones), críticos -requieren Unidad de Cuidados Intensivos (UCI) y fatalidades, generando un modelo SEIR ampliado $(\mathrm{SEIR}+\mathrm{HC})$. El modelo permite trazar la trayectoria de estos grupos, utilizando para ello parámetros tales como el nivel inicial de infecciosos, el factor reproductivo, período de incubación e infeccioso, tasas de hospitalización y criticidad, entre otros.

\footnotetext{
${ }^{1}$ Brauer \& Castillo-Chávez (2012) presentan un relevamiento de los modelos SEIR.
} 
Asimismo, nuestro modelo incorpora extensiones para mejorar su ajuste a las particularidades de cada región: la distribución etaria, y sus correspondientes tasas de severidad y criticidad, el ingreso de casos infecciosos importados, el efecto de medidas de intervenciones no farmacéuticas y restricciones del sistema sanitario local. Además, incorporamos incertidumbre en el modelo a través de variables clave del modelo, de difícil medición para los hacedores de política y de alto impacto en los resultados, estos son: el número de infectados al inicio y la evolución del Factor Reproductivo.

Antes de aplicar nuestro modelo a un caso local, evaluamos el mismo mediante el ajuste a la evolución epidemiológica del virus en regiones con transmisión comunitaria, en particular, el modelo fue calibrado para describir de forma correcta trayectorias pasadas de la epidemia en la Ciudad Autónoma de Buenos Aires (dentro de la muestra). Encontramos un muy buen ajuste del mismo tanto en el número de casos, como hospitalizaciones, requerimientos de unidades de cuidado intensivo, y cantidad de fallecidos, variables de menor dificultad para la medición. Esto nos indica que partiendo del uso y calibración de variables fundamentales el modelo tiene potencial para reproducir las trayectorias epidemiológicas de la región una vez que el virus entra en circulación.

Además, con el objetivo de evaluar la precisión de las proyecciones realizadas testeamos el modelo fuera de la muestra. En particular, calibramos nuestro modelo SEIR+ para Tucumán una vez que la epidemia aumentó su velocidad (hospitalizados superando los 2 mil casos) y proyectamos los siguientes 40 días. Comparando nuestras proyecciones y los datos observados, verificamos que las proyecciones fueron efectivas anticipándose a los datos, las observaciones se encontraron dentro de los intervalos de confianza estimados. Estos resultados aumentan nuestra confianza en la precisión de las proyecciones surgidas del modelo para períodos temporales acotados.

Finalmente, mostramos el uso del modelo a nivel local, aplicándolo a Tucumán y generando una proyección de 60 días, a partir de un escenario con 100 infecciosos, factor reproductivo de 2.1 , medidas de mitigación del 35\%, con sus correspondientes distribuciones de probabilidad, y demás parámetros ajustados en función de lo indicado por la literatura.

Antes de continuar y presentar los resultados del modelo, haremos algunas advertencias. En primer lugar, no somos epidemiólogos, somos economistas, con especial interés en el diseño de políticas públicas. En este contexto, surge nuestra demanda de contar con proyecciones cuantitativas acerca del posible número de infectados, además del transcurso del tiempo en el cual esto puede ocurrir. No encontramos trabajos en progreso que nos permitan conocer cuantitativamente escenarios para el COVID19 a nivel local. En segundo lugar, como presentaremos en detalle, aún existe mucha incertidumbre respecto de parámetros clave del modelo, lo cual agrega incertidumbre a la proyección de los modelos. Finalmente, el modelo desarrollado, principio de parsimonia mediante, simplifica la realidad en numerosas dimensiones, si bien incorpora algunas variables importantes frente a otros modelos naïve. 
La organización del documento es la siguiente. En la segunda sección describimos el comportamiento de las curvas epidemiológicas, que incluyen al COVID-19, destacando las particularidades que hacen a este virus tan especial. En la tercera sección describimos nuestro modelo epidemiológico. En la cuarta sección se discute la parametrización del mismo, de particular importancia dado el efecto de los parámetros en las proyecciones y la incertidumbre que aún existe acerca de ellos. En la quinta sección se presenta el ajuste, dentro de la muestra, del modelo para la Ciudad Autónoma de Buenos Aires y en la sexta sección evaluamos el ajuste fuera de la muestra para Tucumán. En la séptima sección mostramos el uso de modelo a nivel local. Finalmente, en la sección ocho, se presentan las conclusiones.

\section{Curvas epidemiológicas y particularidades del COVID-19}

Lo que se observa en los primeros países donde el COVID-19 se desarrolló (China y Corea del Sur, en particular) es que la Curva de infectados del COVID-19 muestra un comportamiento muy similar al de otras curvas epidemiológicas, como la gripe estacional (Baldwin \& di Mauro, 2020) (ver Anexo). Es decir, en la primera etapa, un crecimiento lento que luego se torna exponencial, en el cual el número absoluto de casos crece día a día, hasta alcanzar un pico a partir del cual la curva comienza su fase decreciente.

La evolución del número de infecciosos puede expresarse, sintéticamente, como la relación entre 3 variables: la población Susceptible de ser Infectada (S), el/los Infecciosos (I), y la vedette de una epidemia, la tasa de contagio (determinada en gran medida por el Factor Reproductivo $R_{0}^{2}$ ). La relación entre estas tres variables, nos permite entender por qué la curva epidemiológica posee esta forma acampanada ${ }^{3}$.

En la primera etapa, el número de infectados son pocos, y en consecuencia son pocas las posibilidades de contagiar. Luego, una vez alcanzada una masa crítica de infecciosos se inicia la etapa de aceleración exponencial. Sin embargo, a medida que crece el stock de Infectados (el cual incluye a los recuperados no infecciosos), disminuye el de personas susceptibles, con lo cual la curva crece a un ritmo cada vez más lento. Esta dinámica implica que existe un límite en el crecimiento de la curva que está dado por el tamaño de la población por lo que el número de Infectados debe necesariamente alcanzar un pico. En caso de que no existan medidas de mitigación tales como cuarentenas o vacunas, el pico de la curva se produce cuando la población alcanza lo que se conoce como herd-immunity (inmunidad de manada) ${ }^{4}$. A partir de este punto la tasa de nuevos

\footnotetext{
${ }^{2}$ El número reproductivo básico $R_{0}$ es un concepto central en epidemiología de enfermedades infecciosas y representa el número promedio de contagios que genera una persona dentro de una población completamente desprevenida .

3 Richard Baldwin realiza una excelente explicación sobre el comportamiento de la EPI (https://www.weforum.org/agenda/2020/03/exponential-economist-epidemiological-curve-coronaviruscovid19/).

${ }^{4}$ El concepto de herd-immunity es una de las razones por las que la vacunación es una política de sanidad pública. Si un individuo, gracias a la micro-infección producto de la vacuna, desarrolla anticuerpos que impidan el alojamiento de un virus en su cuerpo, en ese mismo acto no solo se protege a él mismo de adquirir la enfermedad en el futuro, sino que además está protegiendo a las personas que lo rodean de ser contagiadas por él.
} 
contagios empieza a caer $\left(R_{0}<1\right)$ debido a que la inmunidad desarrollada por gran parte de la población impide que continúe la circulación del virus, entrando en la etapa de decrecimiento de la curva.

Figura 1: Ilustración comportamiento del número de nuevos infectados de una EPI

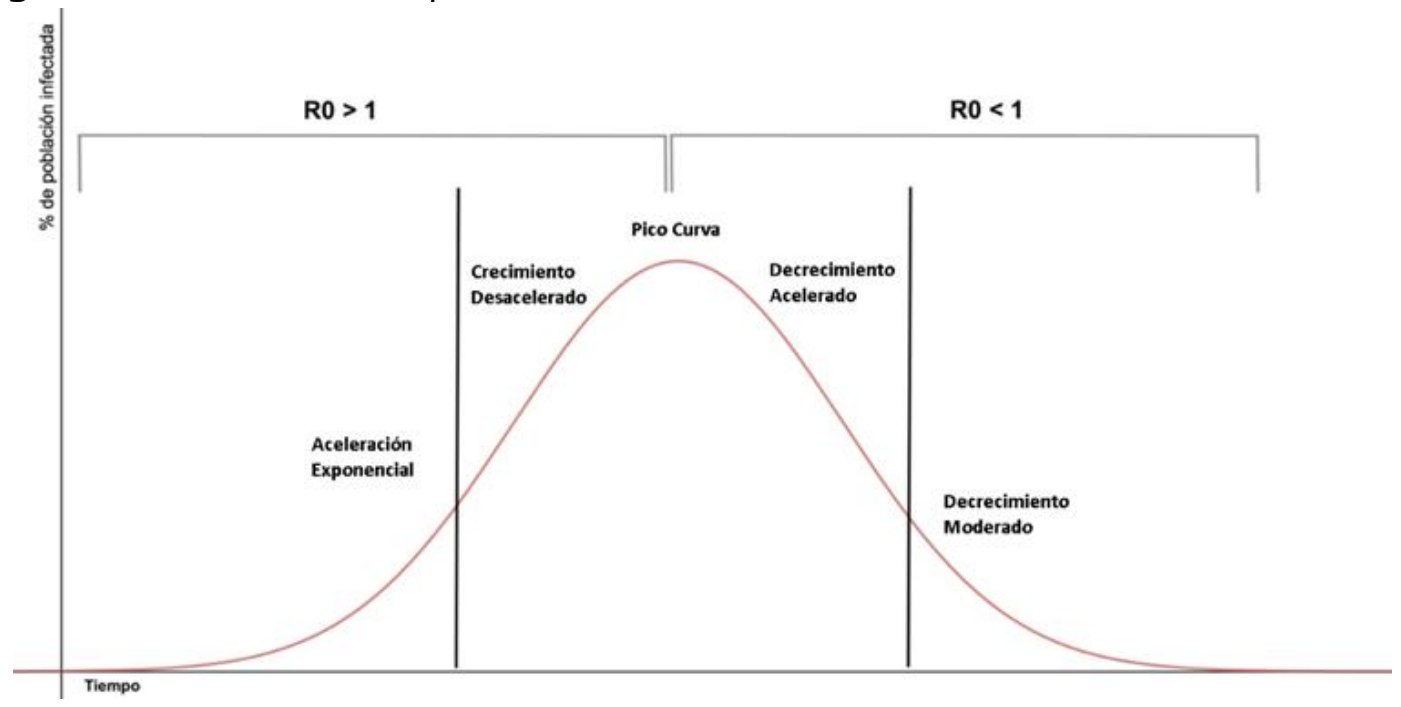

Resumidamente, nótese que la curva epidemiológica no tiene un comportamiento ni lineal ni exponencial en todo su dominio, con lo cual extrapolar su comportamiento en la etapa temprana nos hace subestimar el problema (miopía que sufrieron muchos países que demoraron en tomar medidas para evitar la epidemia), mientras que extrapolar el comportamiento durante la etapa de crecimiento exponencial (como suele ocurrir en los momentos de pánico) nos lleva a sobredimensionar las posibilidades de expansión de la epidemia. Es por esto que la utilización de un modelo de Contagio epidemiológico cobra relevancia para realizar proyecciones que permitan la correcta toma de decisiones.

¿Pero, entonces, qué tiene de distinto la gripe COVID-19 que genera un impacto tan grande en nuestra población? La clave está en dos de sus parámetros, el Factor Reproductivo y la criticidad de la enfermedad. Los infectados de una gripe estacional infectan en promedio a 1.3 personas, mientras que el COVID-19 evidencia tener un rango de contagio 2 o 3 veces superior. Además, mientras que la gripe estacional demanda un $2 \%$ de hospitalización sobre infectados, el COVID-19 se estima demanda alrededor de un $20 \%$. Por supuesto, este último varía de acuerdo a la edad y enfermedades prevalecientes del infectado. Es la conjugación de alta velocidad de contagio y fuertes requerimientos de hospitalización, lo que pone en jaque las capacidades del sistema sanitario. 
Figura 2: Comparación de Gripe Estacional y COVID-19

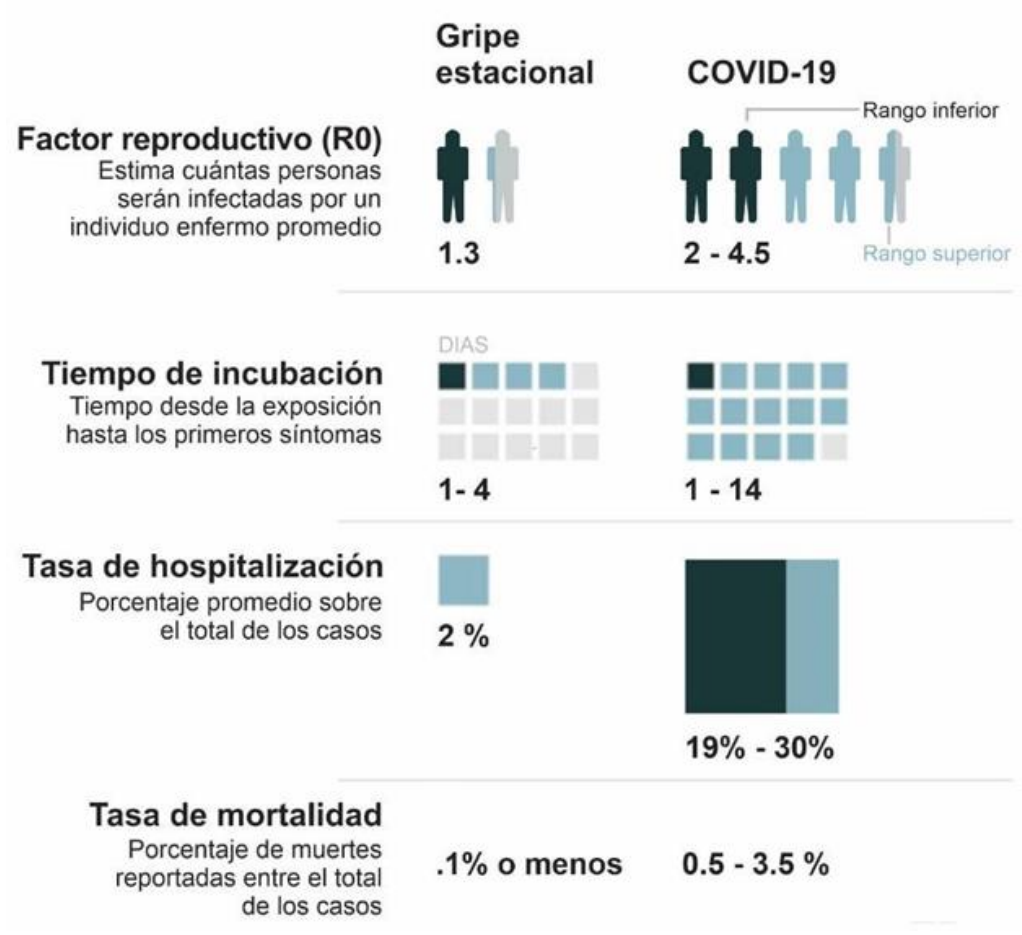

\section{Modelo}

El modelo canónico para la predicción de las epidemias es conocido por sus siglas SEIR (Kermack \& McKendrick, 1927), correspondiente a los cuatro compartimentos o estados de la población: Susceptible, Expuestos; Infectados; Recuperados o "Removidos"5. En nuestro caso, nos basamos en el modelo desarrollado por Neher et al. (2020), el cual suma a estos compartimentos tres grupos sumamente importantes para la planificación del sistema sanitario: enfermos severos (requieren hospitalizaciones), críticos (requieren cuidados intensivos) y fatalidades. Cabe destacar que nuestro modelo SEIR supone una dirección única de un compartimento a otro, i.e. un individuo recuperado no puede volver a ser expuesto ni infectado. El trabajo de Giannitsarou et al. (2020) relaja el mismo, y hace hincapié en la "inmunidad debilitada", dando lugar a la posibilidad de reinfección en ciertos individuos.

El modelo permite trazar la trayectoria de estos grupos utilizando para ello: el número inicial en estos compartimentos (ej. nivel inicial de Infectados, etc.), parámetros de transición entre estados/compartimentos (período de incubación, infeccioso, hospitalización, criticidad), parámetros de severidad de la enfermedad condicionales a cada grupo etario (tasas de hospitalización, criticidad y fatalidad) y, por supuesto, la tasa de transmisión del virus (asociada al factor reproductivo y las medidas de mitigación adoptadas por la sociedad).

\footnotetext{
${ }^{5}$ Este modelo es utilizado por Atkenson (2020), Peng et al. (2020), y Wu et al. (2020), entre otros para el análisis del COVID-19. Brauer \& Castillo-Chávez (2012) presentan un relevamiento de los modelos SEIR.
} 
Entre las riquezas de nuestro modelo, programado mediante el software $R$, se encuentran:

i. Su ajuste a la distribución etaria de la población local, con sus respectivas tasas de severidad. Nótese que, por ejemplo, la proporción mayor a 65 años en Tucumán es la mitad respecto de la de Ciudad de Buenos Aires ( $8 \%$ vs. $16 \%$ ) y la tasa de severidad del COVID-19 se estima al menos 6 veces superior en este grupo respecto de la población menor a 18 años $^{6}$;

ii. El ingreso de infecciosos importados, de particular relevancia en un contexto de contagio en zonas próximas a la región bajo estudio;

iii. Efectos de medidas de mitigación en el Factor Reproductivo, práctica ya habitual en el actual contexto de desarrollo de la pandemia (Flaxman et al., 2020a; 2020b).

Figura 3: Ilustración del Modelo SEIR +

Transmisión del virus $\left(\beta_{t}\right)$

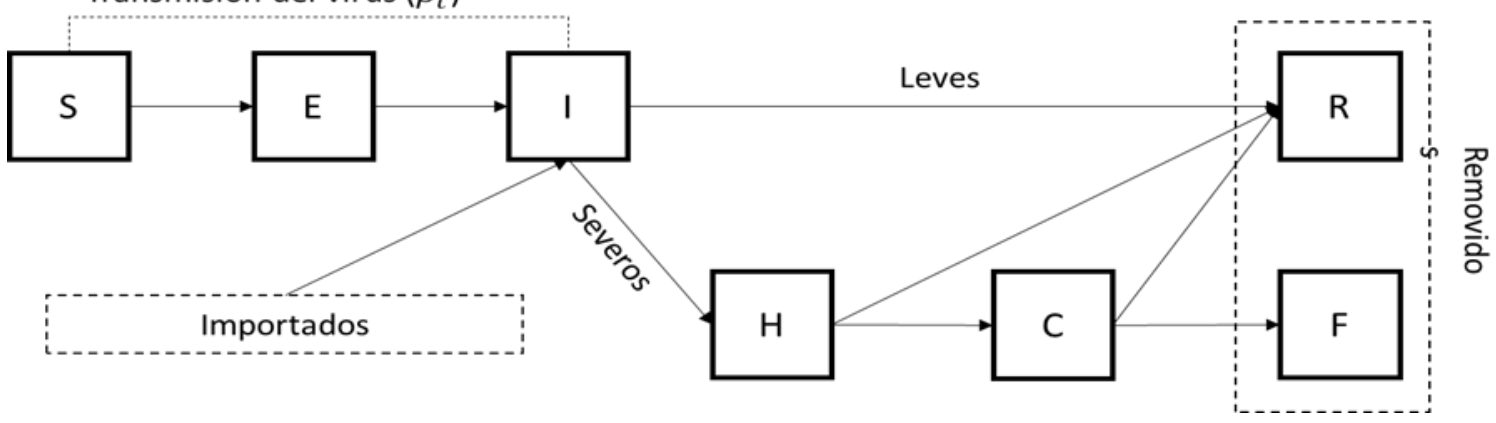

Notas: S: Susceptible; E: Expuestos; I: Infectados, H: Hospitalizados; C: Críticos; F: Fallecidos; R: Recuperados. Fuente: Elaboración propia en base a Noll et al. (2020)

Nuestro modelo resuelve el siguiente sistema de ecuaciones diferenciales, dada unas condiciones iniciales para los compartimentos (Infectados, Expuestos, etc.) y la calibración de los parámetros clave

$$
\begin{aligned}
& S_{a, t+1}=S_{a, t}-\frac{1}{N} \beta_{a, t} S_{a, t} \sum I_{a, t} \\
& E_{a, t+1}=E_{a, t}+\frac{1}{N} \beta_{a, t} S_{a, t} \sum I_{a, t}-\frac{E_{a, t}}{t_{l}} \\
& I_{a, t+1}=I_{a, t}+\frac{E_{a, t}}{t_{l}}-\frac{I_{a, t}}{t_{i}}+I m p_{a t} \\
& H_{a, t+1}=H_{a, t+1}+\frac{\left(1-m_{a}\right) I_{a, t}}{t_{i}}+\left(1-f_{a}\right) \frac{C_{a, t}}{t_{c}}-\frac{H_{a, t}}{t_{h}}
\end{aligned}
$$

\footnotetext{
${ }^{6}$ The Novel Coronavirus Pneumonia Emergency Response Epidemiology Team, 2020.
} 


$$
\begin{aligned}
& C_{a, t+1}=C_{a, t}+c_{a} \frac{H_{a, t}}{t_{h}}-\frac{C_{a, t}}{t_{c}} \\
& R_{a, t+1}=R_{a, t}+m_{a} \frac{I_{a, t}}{t_{i}}+\left(1-c_{a}\right) \frac{H_{a, t}}{t_{h}}+\left(1-f_{a}\right) \frac{C_{a, t}}{t_{c}} \\
& D_{a, t+1}=f_{a} \frac{C_{a, t}}{t_{c}} \\
& \beta_{a, t}=R_{0} M(t) / t_{i}
\end{aligned}
$$

Donde:

- La tasa de transmisión del virus está dada por $\beta_{a}(t)$ : el Factor Reproductivo básico $R_{0}$ y el efecto de las medidas de mitigación $M_{t}$.

- Las personas son expuestas al virus $\left(E_{a, t}\right)$, por el contacto entre los Susceptibles $\left(S_{a, t}\right)$ y los Infecciosos $\left(\sum I_{a, t}\right)$.

- Los Infecciosos pueden desarrollar la enfermedad en forma leve/asintomática $\left(m_{a}\right)$ o en forma severa $\left(H_{a, t}\right)$ y/o crítica $\left(C_{a, t}\right)$.

- Los individuos Recuperados $\left[R_{a, t}\right]$ no pueden infectarse nuevamente. Nótese que, de acuerdo a la WHO, no existe aún evidencia de que una persona recuperada no pueda contagiarse nuevamente?.

- Los subíndices a hacen referencia a los diferentes grupos etarios poblacionales.

\section{1. Incertidumbre}

Como destacamos a lo largo de este trabajo, existe mucha incertidumbre alrededor de numerosos parámetros clave para la calibración del modelo y muchos de ellos están siendo mejor identificados por los nuevos estudios científicos (ej. ver los estudios referidos a los tiempos de latencia e infecciosos en Ganyani et al. (2020)).

En nuestra opinión existen tres aspectos clave, y de difícil medición, para pronosticar la trayectoria de una epidemia, dado que dependen del comportamiento específico de cada sociedad y de la capacidad de diagnóstico del sistema de salud, la cual durante el transcurso de la epidemia suele ser variable ${ }^{8}$. Estos factores son: la identificación del número de infecciosos y expuestos en un momento del tiempo $\left(I_{a, 0}, E_{a, 0}\right)$; el factor reproductivo básico $\left(R_{0}\right)$; y el impacto de las medidas de mitigación implementadas por las autoridades locales $\left(M_{t}\right)$. Es por esto que nuestro modelo es calibrado utilizando una distribución aleatoria normal, con medias y varianzas específicas para cada una de estas variables. Esto nos permite, mediante simulaciones de Montecarlo, hacer proyecciones con intervalos de confianza definidos para cada una de los outputs de interés, que

\footnotetext{
${ }^{7}$ https://www.who.int/news-room/commentaries/detail/immunity-passports-in-the-context-of-covid19\# : : text=There\%20is\%20currently\%20no\%20evidence,multi\%2Dstep\%20process.

8 Una referencia que puede utilizarse para conocer la capacidad de diagnóstico de cada región es la tasa de positividad definida como el ratio de casos positivos por número de test realizados. Para Argentina, la tasa de positividad era $47 \%$ al 2 de Agosto (https://ourworldindata.org/coronavirus-testing). La OMS considera una positividad entre el $3 \%$ y $12 \%$ como benchmark de buena capacidad de diagnóstico.
} 
permitan al hacedor de políticas públicas incorporar esta incertidumbre en las proyecciones.

\section{Revisión de la literatura acerca de las variables y los parámetros del modelo}

Para hacer operativo el modelo SEIR es necesario definir un set de variables y parámetros claves, los cuales determinarán las trayectorias posibles. Entre los parámetros más importantes se encuentran: i) Duración del período de incubación $\left(t_{\text {inc }}\right)$; ii) Duración del período Infeccioso $\left(t_{\text {inf }}\right)$; iii) Tasa de hospitalización y criticalidad $\left(m_{a}, c_{a}\right) ;$ iv $)$ Tasa de letalidad $\left.\left(l_{a}\right) ; \mathrm{v}\right)$ Factor reproductivo básico $\left(\left(R_{0}\right)\right.$ y efectos de las medidas de mitigación $\left(M_{t}\right)$.

i. Período de incubación $\left(t_{i n c}\right)$ : Es el tiempo promedio que los individuos permanecen en el estado E del modelo SEIR. Es decir, el período de incubación es el tiempo transcurrido entre la infección de un individuo por un patógeno y la manifestación de los síntomas o enfermedad que este causa y el período a partir del cual el individuo comienza a infectar ${ }^{9}$. Uno de los estudios más citados sobre el período de incubación de COVID-19 es el de Lauer et al. (2020), que estudia 181 casos reportados fuera de la provincia Hubei (China) ${ }^{10}$, y encuentra que la mediana del período de incubación es 5.1 días $(95 \%$ IC, $4.5-5.8)$ y que el $97.5 \%$ de los pacientes desarrolla síntomas antes del día 11.5 . Este dato se encuentra en línea con lo reportado por Kucharski et al. (2020), Perera et al. (2020), y el reporte de la misión de la OMS a China en febrero 2020. Estos valores son similares también a los períodos de incubación del SARS Y MERS (Jiang et al., 2020) familiares del C19, por lo que existe relativa confianza en estas estimaciones. La principal limitación de estos estudios es que utilizan una muestra de personas con sintomatología aguda, por lo que desconocemos el período para aquellos con síntomas leves.

ii. Período Infeccioso $\left(t_{\text {inf }}\right)$ : Es el tiempo promedio que los individuos permanecen en el estado I del modelo SEIR y determina el período en el que los individuos portadores contagian a los susceptibles. El valor de este parámetro es clave para determinar la duración de la pandemia y también es insumo clave para estimar el parámetro $R_{0}$. Existe poco consenso sobre el valor de $t_{\text {inf }}$ y suele ser determinado de forma simultánea a $R_{0}$, mediante simulaciones y calibraciones generales que permitan copiar las curvas

\footnotetext{
${ }^{9}$ Los síntomas más comunes del COVID-19 son fiebre $(87.9 \%)$, tos $(67.7 \%)$, y fatiga (38.1\%), y son los que se suelen utilizar como referencia para indicar el fin del período de incubación. El inicio del mismo es definido mediante entrevistas a pacientes diagnosticados que puedan indicar el momento o período de contagio, ya sea por viajes a zonas de transmisión comunitaria o por contacto directo con casos diagnosticados.

10 Especialmente excluyendo Wuhan, la primera zona de transmisión comunitaria. El criterio de selección de estos casos es poder seguir el momento estimado del contagio. Dicho esfuerzo no está libre de errores de medición, por lo que los investigadores utilizan intervalos mínimos y máximos, y hacen supuestos funcionales sobre las distribuciones de probabilidad de los datos para estimar el parámetro.
} 
empíricas. Es por ello que existe gran variabilidad en el mismo el cual puede ir desde 1.5 días (Bi et al., 2020) hasta 10 (Sjödin et al.,2020) o incluso 20 días (Shlomai et al., 2020). Una práctica habitual es utilizar el mismo valor que el período de incubación (Read et al., 2020), lo que coincide con lo que se conoce del comportamiento del virus SARS.

iii. Tasa de Hospitalización y criticalidad $\left(m_{a}, c_{a}\right)$ : Conocer las demandas sanitarias de la epidemia es fundamental para conocer si existirán suficientes camas, unidades de terapia intensiva, y respiradores mecánicos, entre otros. Frente a una ola masiva de pacientes con COVID-19, pequeñas diferencias en las estimaciones de requerimientos sanitarios pueden implicar grandes diferencias en las medidas de política que deberán tomarse. Por ejemplo, luego de que Ferguson et al. (2020) ajusta sus parámetros, indicando que dentro de los hospitalizados por COVID-19 no un 15\%, sino un 30\% requeriría camas de terapia intensiva, las predicciones de mortalidad se duplicaron ${ }^{11}$. Existen al menos dos dificultades para realizar estas estimaciones: i) Las necesidades de cuidado son diferentes entre poblaciones, especialmente por las distintas pirámides etarias y la existencia de comorbilidades específicas en cada población. ii) Existen grandes diferencias entre las capacidades de testeo y la detección de casos entre países, por lo que al no conocer el número total de infectados no se puede conocer la tasa efectiva de hospitalizados por cada infectado. De acuerdo a la OMS (Gomes, 2020) el criterio de hospitalización debe ser del $20 \%$ sobre infectados. Ferguson et al. (2020) utiliza tasas menores, pero hace supuestos importantes sobre el número de infectados pues incluye asintomáticos y personas con síntomas leves dentro del grupo de infectados. En relación a estas tasas, Guan et al. (2020), en base a un estudio de 1100 pacientes hospitalizados en China, reporta que el tiempo de hospitalización promedio es de 12 días, siendo 8 para los casos leves y 16 para los que requieren cuidados intensivos (un $16 \%$ de los hospitalizados). A su vez, estima que $6 \%$ requieren respiradores. Las Figuras $4 a$ y $4 b$ muestran las tasas de hospitalización empíricas para la Ciudad Autónoma de Buenos Aires a principios de agosto (2020).

iv. Tasa de letalidad $\left(l_{a}\right)$ : La tasa de letalidad está definida como el número de portadores de SARS-COV-2 que fallecen por cada persona infectada con el virus $^{12}$. Existe una gran controversia sobre el valor efectivo de dicha tasa, en gran parte porque a la fecha no conocemos a ciencia cierta la tasa de portadores asintomáticos del virus que podrían estar entre el $18 \%$ y $75 \%$ de los infectados ${ }^{13}$. A su vez, la tasa de letalidad se ve fuertemente afectada por

\footnotetext{
${ }^{11}$ Estas nuevas predicciones hicieron que el Reino Unido modificara su política sanitaria previa para alinearla con la del resto de Europa (Adam, 2020).

12 Esta ratio no debe confundirse con el impacto en la mortalidad del COVID-19 que implica una interpretación causal sobre el efecto de la enfermedad en la probabilidad de muerte de una persona. Un análisis causal necesita un análisis más sofisticado, que posiblemente utilice excesos de mortalidad, tal como el ejercicio realizado por Barro et al. (2020) para el estudio del impacto de la Gripe Española.

${ }^{13}$ La cota inferior del $18 \%$ corresponde al estudio realizado a bordo del crucero Princess Diamond, el cual tiene el valor de que se testeó a toda la población a bordo del crucero, y no solo los sintomáticos. Sin embargo, la mayor parte de la tripulación tenía más de 60 años y la circulación del virus podría haber intensificado la
} 
la calidad de la atención sanitaria de cada región, la curva etaria de la población, y la prevalencia de comorbilidades tales como deficiencias cardíacas, pulmonares, y diabetes ${ }^{14}$ (Istituto Superiore di Sanita, 2020). Para evitar este tipo de errores debido a la medición, una práctica modelística aconsejable es utilizar tasas de letalidad por cantidad de internados en terapia intensiva, clasificados según edad.

v. Factor reproductivo básico $\left(R_{0}\right)$ : El número reproductivo básico $R_{0}$ es un concepto central en epidemiología de enfermedades infecciosas y representa el número promedio de contagios que genera una persona dentro de una población completamente desprevenida ${ }^{15}$. Estimar $R_{0}$ empíricamente es muy difícil porque para ello se requiere información sobre la cantidad de infectados ${ }^{16}$, que en general no puede ser observado de forma precisa. Así, la cantidad e intensidad de testeo, la presencia de asintomáticos, la definición de casos sospechosos, y las actividades generales de prevención de la enfermedad, afectarán los valores estimados de $R_{0}$. Estos factores intentan ser controlados o modelados por los epidemiólogos, los cuales utilizan criterios diferentes, $y$, también, obtienen resultados diferentes. Liu et al.(2020) encuentra que las estimaciones de $R_{0}$ para China ${ }^{17}$ van desde 1.4 hasta 6.49 , con una mediana de 2.79 y media de 3.28. La Tabla 1 muestra una revisión sobre los valores de $R_{0}$ estimados por diez trabajos.

vi. Intervenciones: Ante el aumento creciente de números de casos y muertes por COVID-19, y con la intención de mantener la capacidad de los sistemas sanitarios de atender los casos severos, las personas y los gobiernos de todo el mundo han implementado diferentes intervenciones "no farmacéuticas" de gran escala. Estas intervenciones incluyen, por ejemplo, medidas de aislamiento individual voluntario (AIV), distanciamiento social (DS), prohibición de eventos públicos (EP), suspensión de clases y actividades académicas (SC), y, más recientemente, medidas de cuarentena generalizada

sintomatología, lo que implicaría una subestimación de la tasa de asintomáticos. La tasa del $75 \%$ es un aproximado, y corresponde a lo informado por un médico a cargo de testear 3000 habitantes en Vo'Euganeo, $50 \mathrm{~km}$ oeste de Venecia. Para una recopilación de algunos estudios además de los citados ver el artículo de Heneghan et al. (2020) COVID-19: What proportion are asymptomatic?

${ }^{14}$ Por un estudio de las tasas de mortalidad por región y edad en base a 70.418 casos reportados en Italia ver el informe publicado regularmente por el Instituto Superior de Sanidad de Italia.

${ }^{15}$ Una vez que la población está alerta de la enfermedad y toma medidas para prevenirla suele analizarse la evolución, en distintos períodos $t$, del valor del índice reproductivo $R_{t}$. $R_{t}$ es un indicador del riesgo de transmisión y expansión de la enfermedad que cuando tiene valores mayores nos indica que el número total de infectados está creciendo (etapa creciente de la EPI). Las políticas de mitigación tales como la cuarentena buscan disminuir el índice reproductivo e idealmente lograr un $R_{t}<1$ (etapa decreciente de la EPI) de manera que disminuya el número diario de infectados. Dentro del modelo SEIR, $R_{0}=\beta *$ tinf $=r$, donde es la probabilidad de transmisión por contacto. Esta representación de $R_{0}$ expresa claramente que cuanto mayor sea la probabilidad de transmisión, y el tiempo infeccioso de la enfermedad, mayor será el factor de reproducción de la misma. También nos dice que cuanto mayor sea la tasa de recuperación de los infectados, menor será $R_{0}$. 16 Una alternativa es estimarlo utilizando el número de decesos. Si bien este dato posee menores errores de medición que el número de infectados, no está exento de dificultades dado los diferentes criterios de clasificación de mortalidades entre países.

${ }_{17}$ La gran mayoría de los investigadores utilizan el período que va desde el 1 de enero al 22 de enero para ajustar sus estimaciones, dado que a partir de allí se decretó la cuarentena en China. 
(CG). La forma y timing de las medidas de intervención varía entre países ${ }^{18}$ (Ministerio de Salud Argentina,2020; Flaxman et al., 2020a), pero todas coinciden en su objetivo de disminuir el índice reproductivo $R_{t}$ y así "aplanar la curva" epidemiológica para amesetar los picos de contagio y ampliar el plazo disponible para acondicionar los sistemas sanitarios. Por ejemplo, Flaxman et al. (2020a) encuentran que las medidas de cuarentena estricta reducen $R_{t}$ alrededor del $75 \%$, mientras que otras medidas como la cancelación de eventos públicos, cierre de escuelas, y distanciamiento social tendrían moderados impactos de entre $0 \%$ y $20 \%$. Es preciso mencionar que, en adición a las medidas de mitigación que puedan ordenar los gobiernos con el fin de mitigar los contagios y por consiguiente el impacto sanitario de la epidemia, los individuos tienden a tomar medidas preventivas en contextos de enfermedades altamente infecciosas.

Figura 4a: Hospitalizados por COVID-19 sobre Confirmados en CABA (por Grupo Etario)

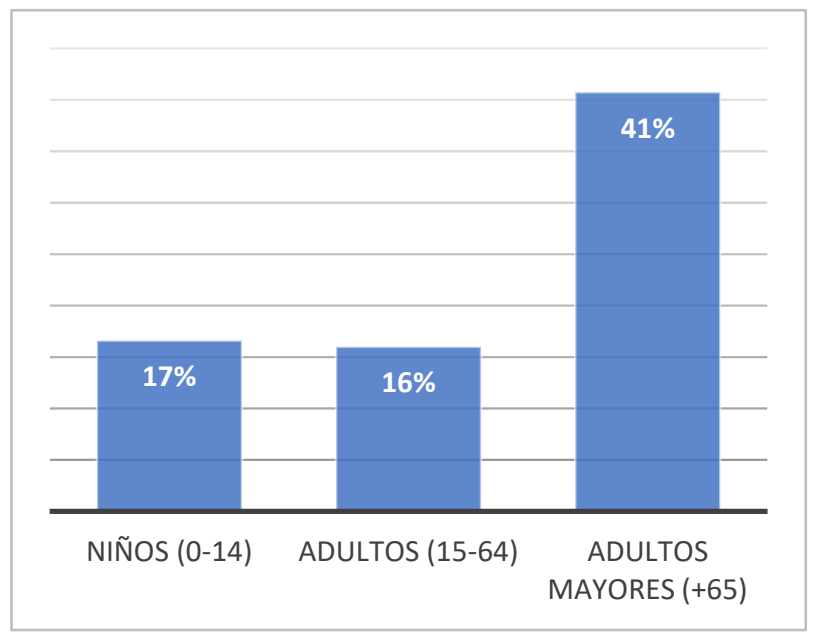

Figura 4b: Casos detectados y Hospitalizados Buenos Aires al 3 de agosto

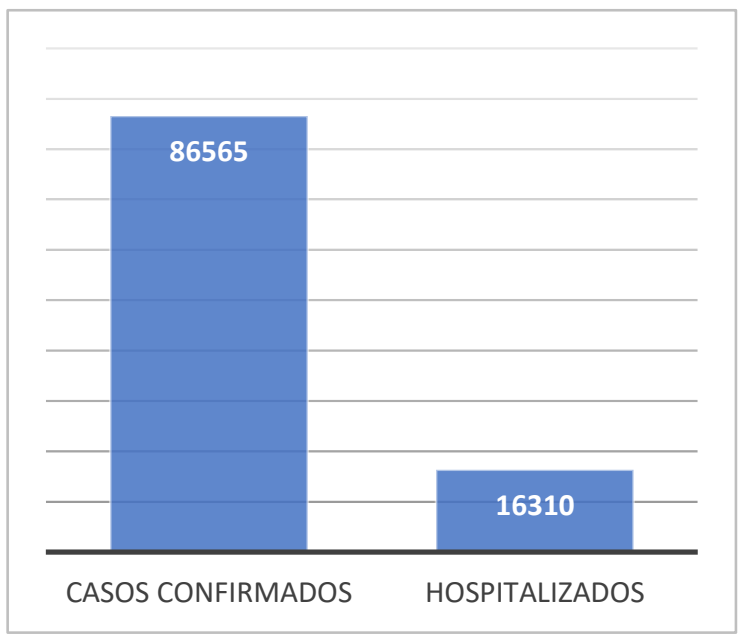

Fuente: elaboración propia en base a datos del Ministerio de Salud de la República Argentina.

\section{Bondad de ajuste del modelo}

Según Eksin et al. (2019) los modelos SEIR simples presentan una gran debilidad a la hora de predecir el número de infectados a mediano o largo plazo debido principalmente a que hacen uso de $R_{0}$ para predecir el sendero de largo plazo de la infección y por ende no incorporan los cambios en el comportamiento de los individuos. Estos autores realizan una simulación modelando el cambio en comportamiento mediante una función de social-distancing, encontrando que, dependiendo de los parámetros, el modelo SEIR

\footnotetext{
18 Para una línea temporal y detalle de medidas tomadas hasta el 19 de marzo en el mundo ver: Sala de Situación COVID-2019 (19/03) - Ministerio de Salud Argentina, p.23. Una recopilación de las medidas tomadas en Europa al 30 de marzo, en inglés, se puede encontrar en el informe del Imperial College London, p.5.
} 
simple sobrestima entre un $85 \%$ y un $250 \%$ el número de contagiados en el pico. Toxvaerd (2020) revela, a partir de un modelo SIR de equilibrio general, que los individuos mediante un proceso de toma de decisiones descentralizado tienden a incrementar de manera endógena el distanciamiento social, aumentando este comportamiento de manera drástica cuando la epidemia alcanza un pico.

Tabla 1: Revisión de literatura sobre $R_{0}$

\begin{tabular}{|c|c|c|c|c|}
\hline Autor & Fecha & $\begin{array}{l}\text { Cobertura } \\
\text { geográfica }\end{array}$ & $\begin{array}{c}\text { Parámetro } \\
\text { (Media aritmética) }\end{array}$ & $\begin{array}{l}\text { Desviación } \\
\text { Estándar }\end{array}$ \\
\hline $\begin{array}{l}\text { Zhuang et al. } \\
\text { (2020) }\end{array}$ & $15-06$ & $\begin{array}{c}\text { Corea del Sur e } \\
\text { Italia }\end{array}$ & $2.6-3.2$ & 0.15 \\
\hline $\begin{array}{l}\text { Khosravi et al. } \\
(2020)\end{array}$ & $19-05$ & Shahroud, Iran & 2.7 & 0.3 \\
\hline Song et al. (2020) & $10-04$ & China & $3.16-3.91$ & - \\
\hline $\begin{array}{l}\text { D'Arienzo \& Coniglio } \\
(2020)\end{array}$ & $31-03$ & Italia & 2.765 & 0.17 \\
\hline Li et al. (2020) & $26-3$ & Wuhan, China & 2.2 & 0.4 \\
\hline $\begin{array}{l}\text { Alimohamadi et al. } \\
(2020)\end{array}$ & $20-03$ & China & 3.38 & 0.7 \\
\hline Chen et al. (2020) & $28-02$ & China & 3.58 & - \\
\hline Wu et al. (2020) & $31-01$ & Wuhan, China & 2.68 & 0.1 \\
\hline Zhao et al. (2020) & $27-01$ & China & $2.24-3.58$ & $0.14-0.35$ \\
\hline $\begin{array}{l}\text { Majunder \& Mandel } \\
\text { (2020) }\end{array}$ & $26-01$ & Wuhan, China & 2.55 & 0.27 \\
\hline
\end{tabular}

Notas: los casos en los que la columna de parámetros exhibe más de un valor, los mismos corresponden a un límite inferior y superior, respectivamente. Fuente: elaboración propia.

Shen et al. (2020) refuerza este argumento mencionando que el hecho de no tener en cuenta la sensibilidad de la curva epidemiológica a las distintas intervenciones (gubernamentales y de los individuos) hace las simulaciones poco realistas. A su vez, refutan los modelos SEIR en general, debido a que estos no permiten incorporar las condiciones del mundo real, principalmente la dinámica interactiva local y cómo estas afectan los parámetros, distribuciones no-normales del número de infecciones por persona y la fluctuación de los parámetros causados por las diferencias en distribuciones muestrales como así también la respuesta de estos parámetros a los cambios sociales. En contraste con lo anterior, Hu et al. (2020) presentan un modelo SEIR que predice con relativamente buena precisión los casos de infectados y el pico para el caso de China.

Dada la heterogeneidad local en el desarrollo de esta epidemia es posible mirar el comportamiento de nuestro modelo para otros países o regiones en donde la epidemia se encuentra en desarrollo y comparar los datos de infectados, hospitalizados, críticos y fatalidades observados y estimados. En nuestro caso lo que hacemos es ajustar el modelo mediante el Factor reproductivo de contagio que minimice los errores cuadráticos 
de las fatalidades acumuladas, ajustando el resto de los parámetros a los valores indicados en la literatura previa. Es decir,

$$
\hat{R}_{0}=(f-\hat{f})^{2} \quad \text { s.a. modelo SEIRHC y parámetros calibrados }
$$

Figura 5: Ajuste Modelo SEIR para datos observados en CABA

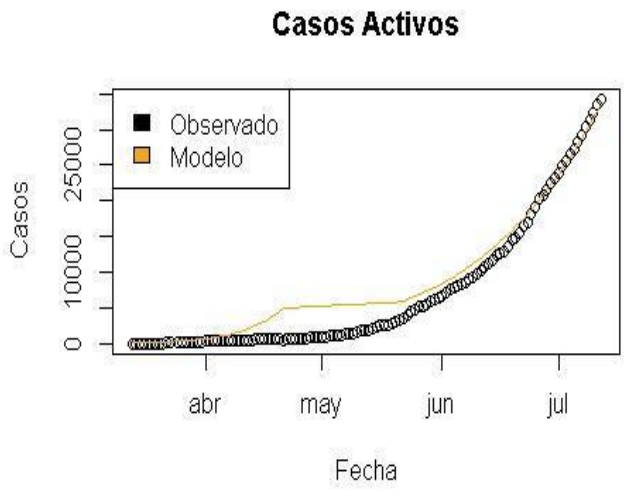

Hospitalizados

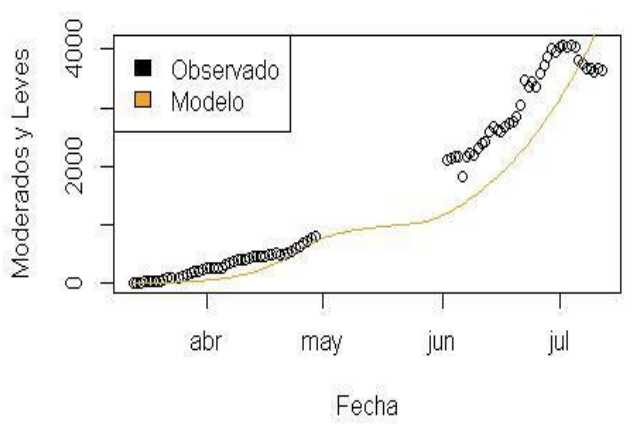

\section{Fallecidos}

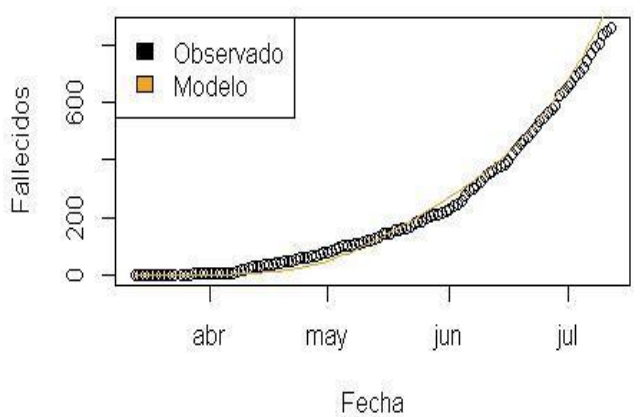

Terapia Intensiva

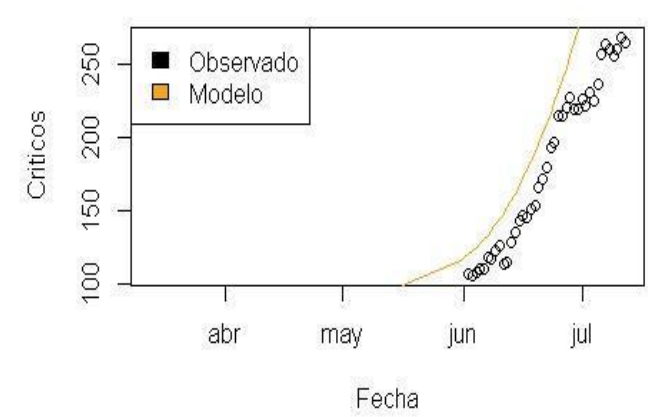

Notas: Ajuste del modelo SEIR para Casos Activos, Fallecidos, Hospitalizados Leves y Moderados, y para camas de Terapia Intensiva. Se lo contrasta con lo observado entre 13-Mar y 12-Jul en CABA. Los resultados surgen de un $\mathrm{RO}=2.1$, sumado a una intervención que simula el impacto de la cuarentena en dos fases a partir de los días 21Abr y $22-$ May reduciéndolo en un $50 \%$ y $35 \%$ respectivamente. Fuente: elaboración propia.

En la Figura 5 mostramos el ajuste de nuestro modelo al comportamiento de la epidemia en CABA. En particular, las estimaciones del número de casos activos, hospitalizados con patologías leves y moderadas, Unidades de Terapia Intensiva y Fallecidos de nuestro modelo es muy similar a los observados en los datos informados por el Ministerio de Salud de CABA. Además, el Ro que resulta de la minimización (2.1) está en línea con lo estimado por la literatura, lo cual refuerza el buen funcionamiento del modelo (ver Figura $6)$. 
Figura 6: Estimación $R_{0}$ óptimo

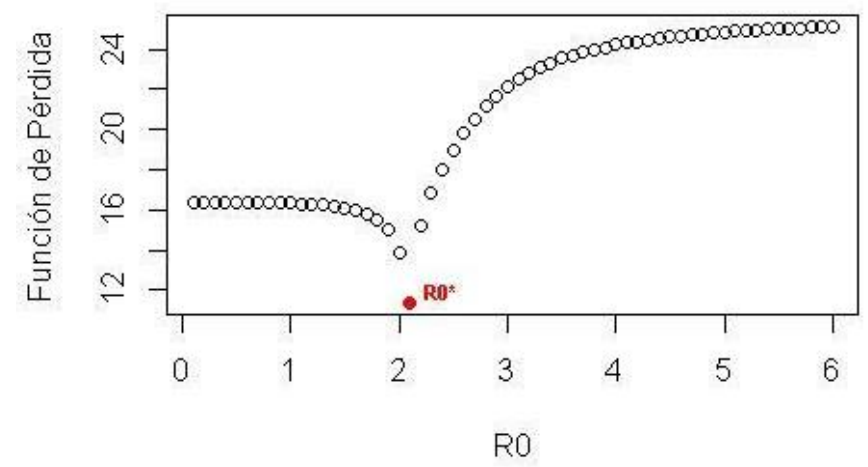

\begin{abstract}
Notas: Cada punto representa el log. de la suma cuadrada de los desvíos de la función de muertes acumuladas estimada por el modelo SEIR respecto de las muertes observadas entre el 13-Mar y 12-Jul en CABA. Este ejercicio se repite para una grilla de R0 entre 0 y 6 , encontrando que $\mathrm{R} 0=2.1$ es el que minimiza la función de pérdida y ofrece el mejor ajuste. Fuente: Elaboración propia.
\end{abstract}

\title{
VI. Ajuste fuera de la muestra: el caso de Tucumán
}

En la sección anterior, mostramos como calibrando el modelo con especial atención al parámetro $R_{0}$ es posible reproducir series de datos epidemiológicos con relativa precisión. Sin embargo, es importante remarcar que dicho ejercicio es realizado ex-post, es decir, luego de que las variables epidemiológicas se realizaron efectivamente, y para ello utilizamos toda la información disponible con el objetivo de imitar las series observadas.

Dado que uno de los objetivos de los modelos SEIR+ es anticiparse a las tendencias en los contagios para asistir la planificación de los hacedores de políticas públicas, nos preguntamos además si las proyecciones del modelo se asemejan a datos futuros.

Para testear el ajuste fuera de la muestra, utilizamos la misma metodología detallada anteriormente y calibramos nuestro modelo SEIR+ con datos observados en Tucumán entre el 1ro de agosto y el 29 de septiembre de 2020. Estos fueron los meses en los que la pandemia empezó a tomar ímpetu en la provincia de Tucumán, los decesos acumulados aumentaron desde un puñado hasta casi 300 , ocurriendo lo mismo con los hospitalizados que llegaron a aproximadamente 2 mil En base a esta información, proyectamos los siguientes 40 días de las series epidemiológicas y pasado ese periodo y verificamos si es que las proyecciones habían sido similares a los datos observados.

En la Figura 7 podemos ver la comparación entre las proyecciones y lo observado para el caso de decesos acumulados. La misma nos muestra cómo las proyecciones realizadas por el modelo SEIR+ fueron efectivas anticipándose a los datos realizados pues salvo en unos pocos casos, las observaciones se encontraron dentro de los intervalos de confianza estimados. Para distinguir este ejercicio de lo realizado en la sección anterior es importante destacar que en aquella oportunidad el ajuste de los datos surge por 
construcción, pues el mismo se realiza utilizando todos los datos dentro de la muestra, mientras que en esta oportunidad el ajuste del modelo se realiza utilizando solo una parte de los datos presentados, por lo que se trata de un ajuste fuera de la muestra. Los resultados presentados en esta sección son alentadores y aumentan nuestra confianza en la precisión de las proyecciones surgidas del modelo para periodos temporales acotados.

Figura 7: Ajuste fuera de la muestra

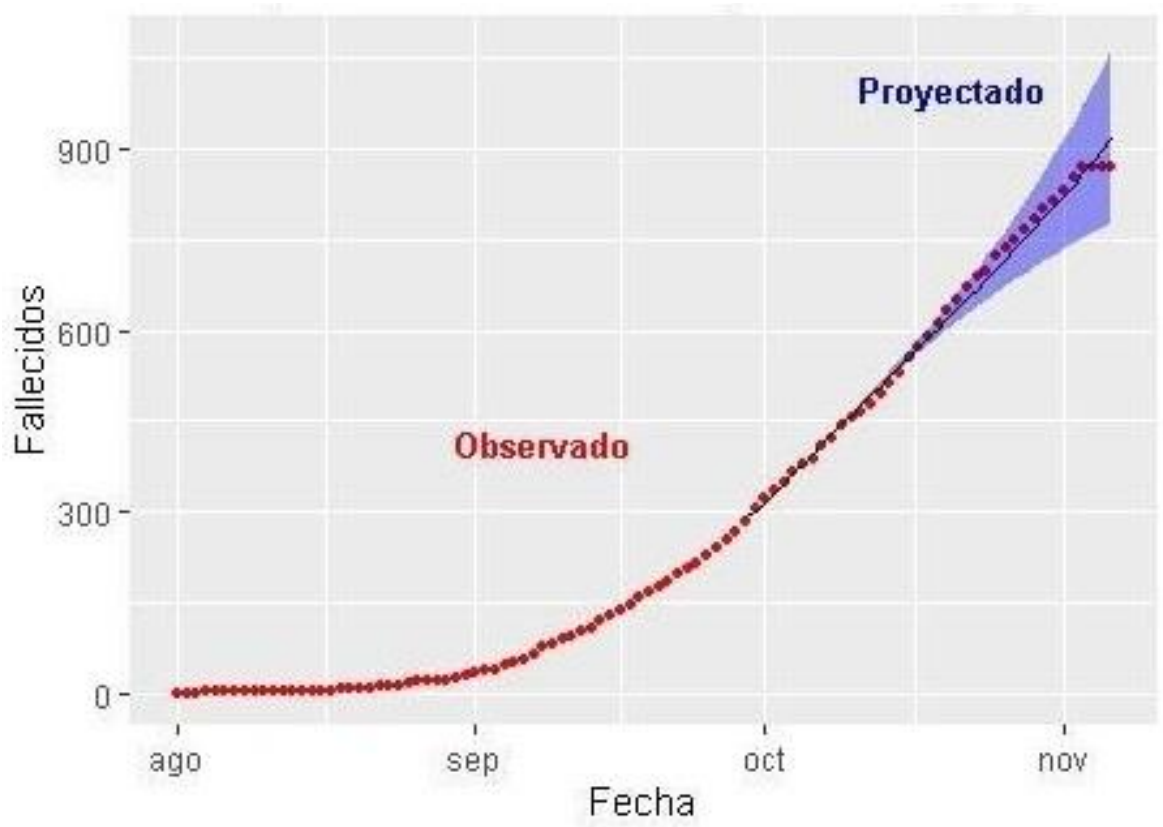

Notas: cada punto representa rojo representa la cantidad de fallecidos acumulados a la fecha en la Provincia de Tucumán. La línea negra es la proyección media del modelo SEIR+ realizada para el periodo 29Sep a 6-Nov de 2020. El área sombreada representa un intervalo de confianza del $90 \%$ para nuestras estimaciones. Fuente: elaboración propia.

\section{Aplicación local: el caso de Tucumán}

Habiendo descrito el modelo y presentado evidencia respecto de su buen ajuste dentro y fuera de la muestra, a continuación, mostramos su uso calibrándolo a un caso local (Tucumán, Argentina), de acuerdo a los parámetros detallados en la Tabla 2. En síntesis, se proyecta un escenario para los próximos 60 días, para la población y distribución etaria de Tucumán, con una esperanza de contagios de 100 (70 expuestos y 30 infecciosos), factor reproductivo básico $\left(R_{0}\right)$ de 2.1, un factor de mitigación del 35\% (con sus respectivas desviaciones estándar) y otros modelos calibrados de acuerdo a la revisión de la literatura. 
Tabla 2: Parámetros de Calibración de un Modelo SEIR para Tucumán

\begin{tabular}{|c|c|c|c|}
\hline \multicolumn{4}{|c|}{ Parámetros Modelo SEIR Tucumán } \\
\hline Población total & $1,448,188$ & \multirow[b]{2}{*}{ Intervención (60 días) } & Media: $35 \%$ \\
\hline Distribución etaria & $\begin{array}{c}\text { Tucumán } \\
\text { (censo) }\end{array}$ & & Sd: $1 \%$ \\
\hline \multirow[b]{2}{*}{ Expuestos inicial } & \multirow{2}{*}{$\begin{array}{c}\text { Media: } 70 \\
\text { Sd: } 5\end{array}$} & Días de incubación & 5 \\
\hline & & $\begin{array}{l}\text { Días de duración de } \\
\text { infección }\end{array}$ & 4 \\
\hline \multirow{2}{*}{ Infecciosos inicial } & \multirow{2}{*}{$\begin{array}{c}\text { Media: } 30 \\
\text { Sd: } 5\end{array}$} & Días de hospitalización & 8 \\
\hline & & Días en UTI & 8 \\
\hline $\begin{array}{l}\text { Casos Importados } \\
\text { por día }\end{array}$ & 0.5 & \multirow[t]{2}{*}{ Factor Reproductivo RO } & \\
\hline \multirow{2}{*}{$\begin{array}{l}\text { Cantidad } \\
\text { Simulaciones }\end{array}$} & \multirow{2}{*}{1000} & & Sd: 0.1 \\
\hline & & Periodo Simulado & 60 días \\
\hline
\end{tabular}

Fuente: elaboración propia.

Los resultados presentados hacen referencia a la evolución de los infecciosos (nótese su diferencia respecto al número total de contagios informados, debido al testeo y debido al outflow), demanda de hospitalizaciones y cuidados intensivos. Entendemos que estas tres variables son los principales insumos para diseñar una estrategia sanitaria. Especial atención, además de a los valores centrales, debe prestarse a los intervalos de confianza expresados por la presentación de los límites delimitados por los deciles 1 y 9.

El número de infectados (infecciosos y expuestos) el cual comienza en 100, alcanza en un mes un total de 330 y finaliza los 60 días con aproximadamente 1.100 . Nótese que las "pequeñas" desviaciones estándar en estos parámetros claves generan intervalos de confianza del $90 \%$ con límites inferiores y superiores que se alejan un $40 \%$ de la media.

En el caso de las personas que requieren cuidados intermedios (hospitalizados), se estima a los 30 días un número de 32 hospitalizaciones (con un rango entre 27 y 38 ) y a los 60 días este valor alcanza los 112 (rango entre 73 y 160). Para los cuidados intensivos, se estima a los 30 días 3 pacientes con requerimientos de UCI y a los 60 días 11 (rango entre 7 y 15). Finalmente, las fatalidades se estiman podrían alcanzar entre 14 y 22 de los infecciosos.

En un marco de incertidumbre respecto de las políticas del gobierno y la respuesta de los habitantes, el modelo se presenta como una herramienta útil para analizar distintos escenarios respecto de las demandas al sistema sanitario. Sin embargo, las estimaciones puntuales de los números de infectados y muertes deben ser tomadas con cautela pues pequeños cambios en el comportamiento de la población, producen importantes diferencias en los resultados de largo plazo. 
Figura 8: Proyección de expuestos e infecciosos para Tucumán

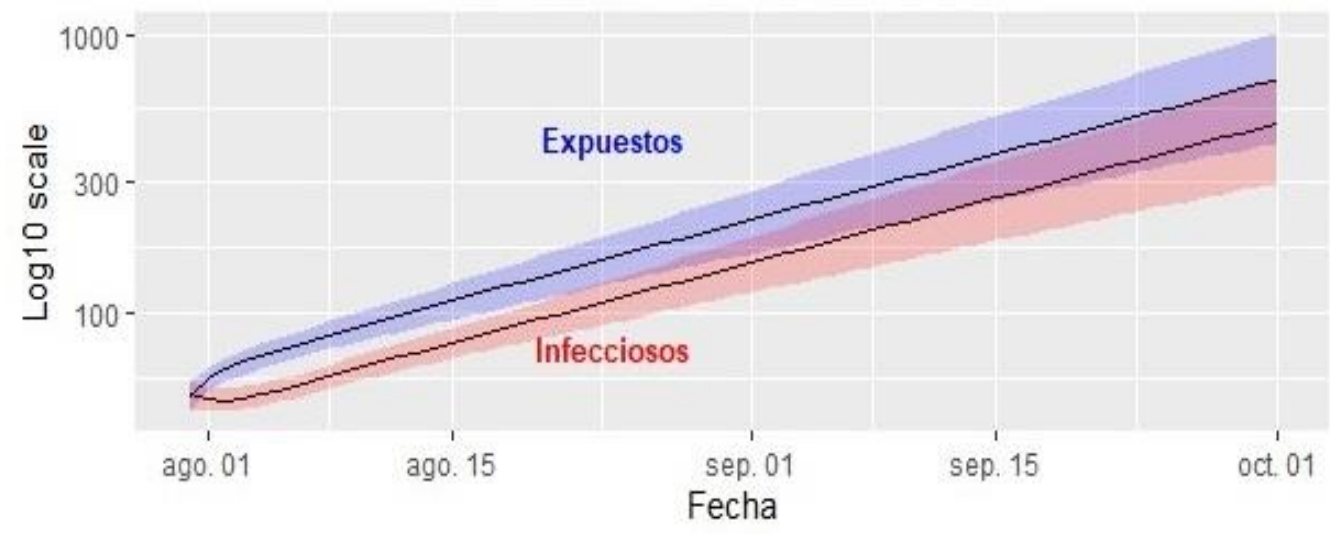

Nota: Bandas de confianza al $80 \%$.

Figura 9: Proyección de demanda de Cuidados Intermedios en Tucumán

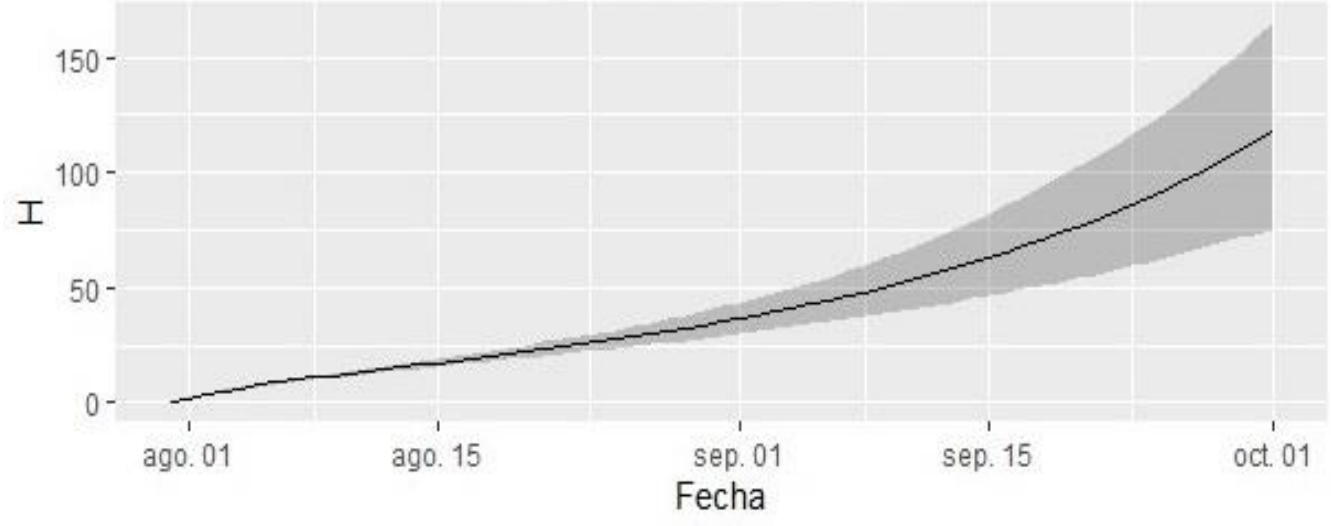

Figura 10: Proyección de demanda de Cuidados Intermedios en Tucumán

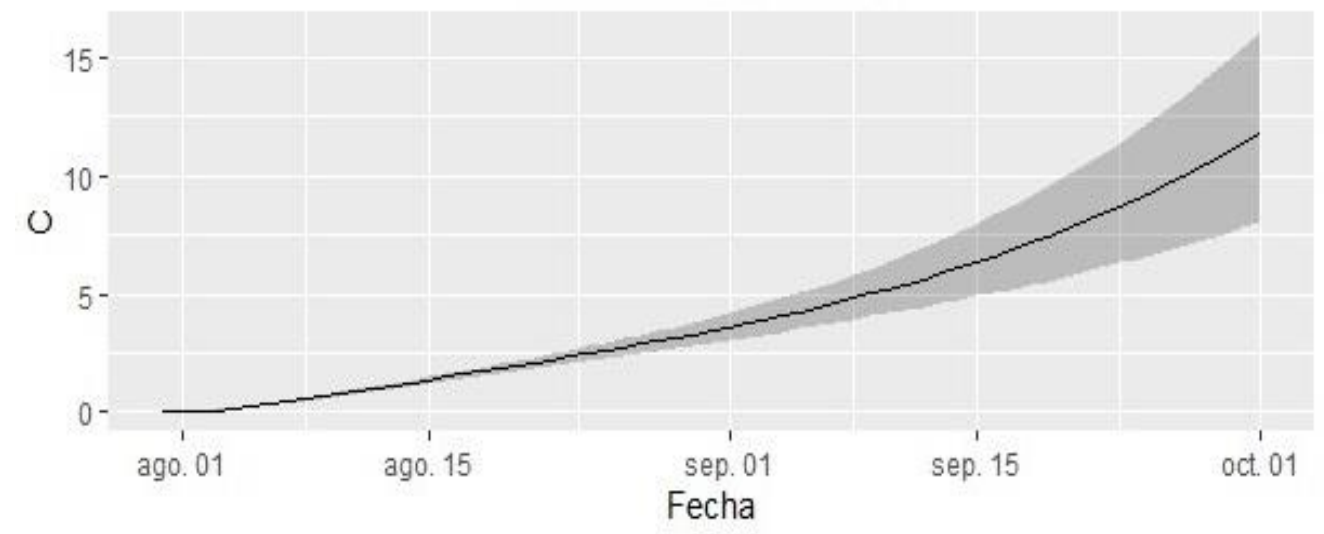




\section{Conclusiones}

Elaboramos y calibramos un modelo SEIR que además de los cuatro estados principales del modelo SEIR clásico, describe la trayectoria de enfermos severos y críticos, estados esenciales para la planificación del sistema de salud. Además, sumamos particularidades locales, como ser la curva etaria de la población y medidas de mitigación que impacten en el factor reproductivo, los cuales varían geográficamente y hacen que el factor local importe. Asimismo, incorporamos la incertidumbre en variables claves asociadas al virus y de difícil proyección para el hacedor de políticas mediante un modelo estocástico.

Para testear el modelo examinamos su bondad de ajuste dentro y fuera de la muestra, para dos regiones diferentes. En primer lugar, examinamos la bondad de ajuste para la evolución de la enfermedad en la Ciudad Autónoma de Buenos Aires y encontramos un muy buen ajuste respecto de evolución del número de casos infecciosos, hospitalizados leves y moderados, demandas de cuidado intensivo y fallecidos. Describir estas trayectorias es posible gracias a la identificación de parámetros estimados de forma empírica en el trabajo y otros estimados previamente por la literatura. En segundo lugar, testeamos el modelo mediante una proyección fuera de la muestra para Tucumán y los datos observados se mantienen dentro de los intervalos de confianza predichos por el modelo.

Finalmente, para mostrar el uso del modelo, proyectamos posibles escenarios futuros para la trayectoria epidemiológica del COVID-19 en la provincia de Tucumán, cuando se inicia la transmisión comunitaria. Esperamos que esta herramienta pueda ser de utilidad para la previsión de necesidades sanitarias de la provincia y para la toma de decisiones sobre políticas de mitigación del COVID-19. 


\section{Referencias}

Adam, D. (2020). Special report: The simulations driving the world's response to COVID19. Nature, 580(7802), 316-319.

Alimohamadi, Y., Taghdir, M., \& Sepandi, M. (2020). The estimate of the basic reproduction number for novel coronavirus disease (COVID-19): a systematic review and meta-analysis. Journal of Preventive Medicine and Public Health, 53(3), 151-157.

Atkeson, A. (2020a). How deadly is COVID-19? Understanding the difficulties with estimation of its fatality rate. Working Paper No. w26965, National Bureau of Economic Research, Cambridge, Massachusetts.

Atkeson, A. (2020b). What will be the economic impact of COVID-19 in the US? Rough estimates of disease scenarios. Working Paper No. w26867, National Bureau of Economic Research, Cambridge, Massachusetts.

Baldwin, R., \& di Mauro, B. W. (Eds.) (2020). Economics in the Time of COVID-19. CEPR Press, Centre for Economic Policy Research, London.

Berger, D. W., Herkenhoff, K. F., \& Mongey, S. (2020). An SEIR infectious disease model with testing and conditional quarantine. Working Paper No. w2690, National Bureau of Economic Research, Cambridge, Massachusetts.

Bi, Q., Wu, Y., Mei, S., Ye, C., Zou, X., Zhang, Z.... \& Gao, W. (2020). Epidemiology and Transmission of COVID-19 in Shenzhen China: Analysis of 391 cases and 1,286 of their close contacts. MedRxiv.

Brauer, F., Castillo-Chavez, C., \& Castillo-Chavez, C. (2012). Mathematical Models in Population Biology and Epidemiology (Second edition). Springer.

Chen, T. M., Rui, J., Wang, Q. P., Zhao, Z. Y., Cui, J. A., \& Yin, L. (2020). A mathematical model for simulating the phase-based transmissibility of a novel coronavirus. Infectious diseases of poverty, 9(1), 1-8.

D'Arienzo, M., \& Coniglio, A. (2020). Assessment of the SARS-CoV-2 basic reproduction number, R0, based on the early phase of COVID-19 outbreak in Italy. Biosafety and Health, 2(2), 57-59.

Eksin, C., Paarporn, K., \& Weitz, J. S. (2019). Systematic biases in disease forecastingThe role of behavior change. Epidemics, 27, 96-105.

Ferguson, N., Laydon, D., Nedjati Gilani, G., Imai, N., Ainslie, K., Baguelin, M. ... \& Dighe, A. (2020). Report 9: Impact of non-pharmaceutical interventions (NPIs) to reduce COVID-19 mortality and healthcare demand. Imperial College London.

Flaxman, S., Mishra, S., Gandy, A., Unwin, J.T... \& Bhatt, S. (2020a). Estimating the effects of non-pharmaceutical interventions on COVID-19 in Europe. Nature, 584(7820), 257-261.

Flaxman, S., Mishra, S., Gandy, A., Unwin, H., Coupland, H., Mellan, T. ... \& Schmit, N. (2020b). Report 13: Estimating the number of infections and the impact of non- 
pharmaceutical interventions on COVID-19 in 11 European countries. Imperial College London.

Ganyani, T., Kremer, C., Chen, D., Torneri, A., Faes, C., Wallinga, J., \& Hens, N. (2020). Estimating the generation interval for coronavirus disease (COVID-19) based on symptom onset data, March 2020. Eurosurveillance, 25(17), 2000257.

Giannitsarou, C., Kissler, S., \& Toxvaerd, F. (2020). Waning immunity and the second wave: Some projections for SARS-CoV-2. American Economic Review: Insights (forthcoming).

Gomes, C. (2020). Report of the WHO-China Joint Mission on Coronavirus Disease 2019 (COVID-19). Brazilian Journal of Implantology and Health Sciences, 2(3).

Guan, W. J., Ni, Z. Y., Hu, Y., Liang, W. H., Ou, C. Q., He, J. X., .. \& Du, B. (2020). Clinical characteristics of coronavirus disease 2019 in China. New England Journal of Medicine, 382(18), 1708-1720.

He, J., Guo, Y., Mao, R., \& Jiming, Z. (2020). Proportion of asymptomatic coronavirus disease 2019 (COVID-19): a systematic review and meta-analysis. Journal of Medical Virology, 93(2), 820-830.

Heneghan, C., Brassey, J., \& Jefferson, T. (2020). COVID-19: What proportion are asymptomatic? The Centre for Evidence-Based Medicine.

Hu, Z., Ge, Q., Jin, L., \& Xiong, M. (2020). Artificial intelligence forecasting of COVID19 in china. arXiv:2002.07112.

Jiang, X., Rayner, S., \& Luo, M. H. (2020). Does SARS-CoV-2 has a longer incubation period than SARS and MERS? Journal of Medical Virology, 92(5), 476-478.

Ministerio de Salud Argentina (2020). Sala de Situación COVID-2019 (19/03), 23.

Kermack, W. O., \& McKendrick, A. G. (1927). A contribution to the mathematical theory of epidemics. Proceedings of the Royal Society of London. Series A, Containing Papers of a Mathematical and Physical Character, 115(772), 700-721.

Khosravi, A., Chaman, R., Rohani-Rasaf, M., Zare, F., Mehravaran, S., \& Emamian, M. $\mathrm{H}$. (2020). The basic reproduction number and prediction of the epidemic size of the novel coronavirus (COVID-19) in Shahroud, Iran. Epidemiology \& Infection, 148, 1-7.

Kucharski, A. J., Russell, T. W., Diamond, C., Liu, Y., Edmunds, J., Funk, S., ... \& Davies, N. (2020). Early dynamics of transmission and control of COVID-19: a mathematical modelling study. The Lancet Infectious Diseases, 20(5), 553-558.

Lauer, S. A., Grantz, K. H., Bi, Q., Jones, F. K., Zheng, Q., Meredith, H. R., ... \& Lessler, J. (2020). The incubation period of coronavirus disease 2019 (COVID-19) from publicly reported confirmed cases: estimation and application. Annals of Internal Medicine, 172(9), 577-582.

Li, Q., Guan, X., Wu, P., Wang, X., Zhou, L., Tong, Y., ... \& Xing, X. (2020). Early transmission dynamics in Wuhan, China, of novel coronavirus-infected pneumonia. The New England Journal of Medicine, 382(13), 1199-1207. 
Liu, Y., Gayle, A. A., Wilder-Smith, A., \& Rocklöv, J. (2020). The reproductive number of COVID-19 is higher compared to SARS coronavirus. Journal of Travel Medicine, 27(2).

Neher, R., Aksamentov, I., Noll, N., Albert, J., \& Dyrdak, R. (2020). COVID-19 scenarios.

Perera, R. A., Mok, C. K., Tsang, O. T., Lv, H., Ko, R. L., Wu, N. C., ... \& Peiris, M. (2020). Serological assays for severe acute respiratory syndrome coronavirus 2 (SARS-CoV-2), March 2020. Eurosurveillance, 25(16), 2000421.

Read, J. M., Bridgen, J. R., Cummings, D. A., Ho, A., \& Jewell, C. P. (2020). Novel coronavirus 2019-nCoV: early estimation of epidemiological parameters and epidemic predictions. MedRxiv.

Shen, C., Taleb, N., \& Bar-Yam, Y. (2020). Review of Ferguson et al "Impact of nonpharmaceutical interventions..." New England Complex Systems Institute, School of Engineering, New York University.

Shlomai, A., Leshno, A., Sklan, E. H., \& Leshno, M. (2020). Global versus focused isolation during the SARS-CoV-2 pandemic-A cost-effectiveness analysis. MedRxiv.

Sjödin, H., Wilder-Smith, A., Osman, S., Farooq, Z., \& Rocklöv, J. (2020). Only strict quarantine measures can curb the coronavirus disease (COVID-19) outbreak in Italy, 2020. Eurosurveillance, 25(13), 2000280.

Song, Q. Q., Zhao, H., Fang, L. Q., Liu, W., Zheng, C., \& Zhang, Y. (2020). Study on assessing early epidemiological parameters of coronavirus disease epidemic in China. Zhonghua liu xing bing xue za zhi=Zhonghua liuxingbingxue zazhi, 41(4), 461-465.

Task force COVID-19 (2020). Epidemia COVID-19, Aggiornamento nazionale: 23 marzo 2020. Dipartimento Malattie Infettive e Servizio di Informatica, Istituto Superiore di Sanità, Italia.

Toxvaerd, F. (2020). Equilibrium Social Distancing. Cambridge Working Papers in Economics CWPE2021, Faculty of Economics, University of Cambridge https://doi.org/10.17863/CAM.52489

Wilder-Smith, A., Chiew, C. J., \& Lee, V. J. (2020). Can we contain the COVID-19 outbreak with the same measures as for SARS? The Lancet Infectious Diseases, 20(5), e102-e107.

Wu, J. T., Leung, K., \& Leung, G. M. (2020). Nowcasting and forecasting the potential domestic and international spread of the 2019-nCoV outbreak originating in Wuhan, China: a modelling study. The Lancet, 395(10225), 689-697.

Zhao, S., Lin, Q., Ran, J., Musa, S. S., Yang, G., Wang, W., ... \& Wang, M. H. (2020). Preliminary estimation of the basic reproduction number of novel coronavirus (2019nCoV) in China, from 2019 to 2020: A data-driven analysis in the early phase of the outbreak. International Journal of Infectious Diseases, 92, 214-217.

Zhuang, Z., Zhao, S., Lin, Q., Cao, P., Lou, Y., Yang, L., ... \& Xiao, L. (2020). Preliminary estimating the reproduction number of the coronavirus disease (COVID-19) outbreak in Republic of Korea and Italy by 5 March 2020. International Journal of Infectious Diseases, 95, 308-310. 


\section{Anexo}

Figura A1: Curva Gripe Estacional en Estados Unidos (1997 a 2003)

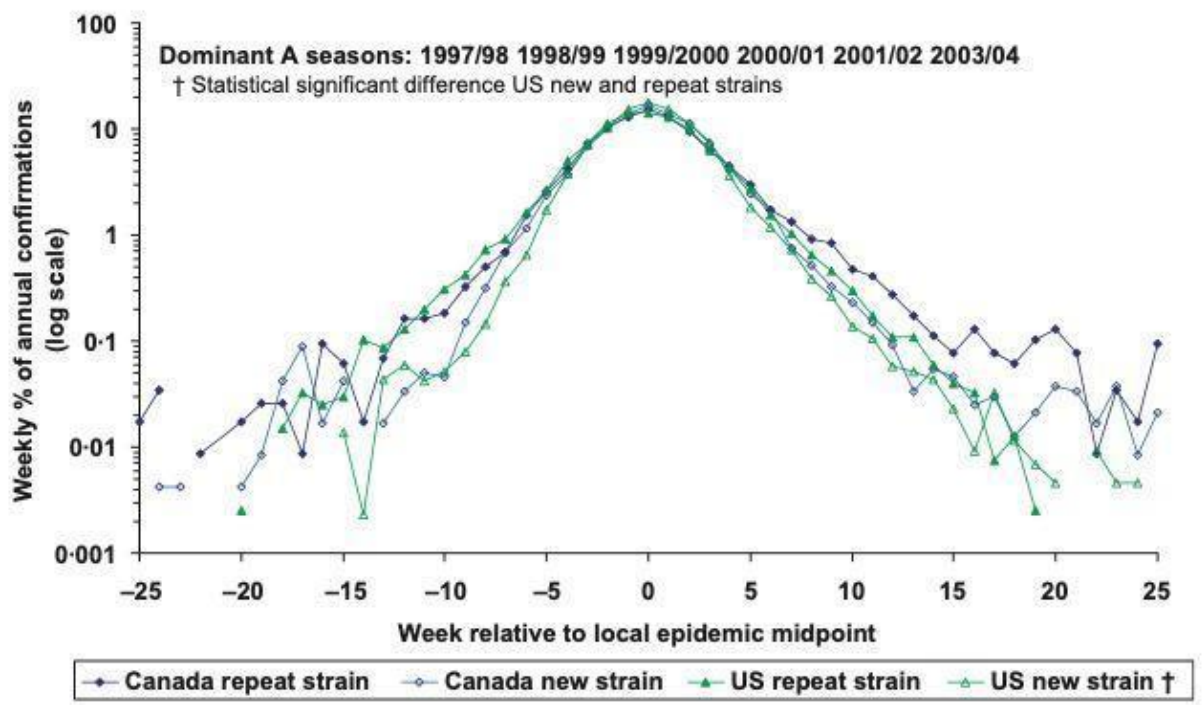

Fuente: Center for Disease Control Prevention

Figura A2: Impacto de las Políticas Públicas en Europa sobre $R t$

$\nmid$ First Intervention $\quad$ Later Intervention

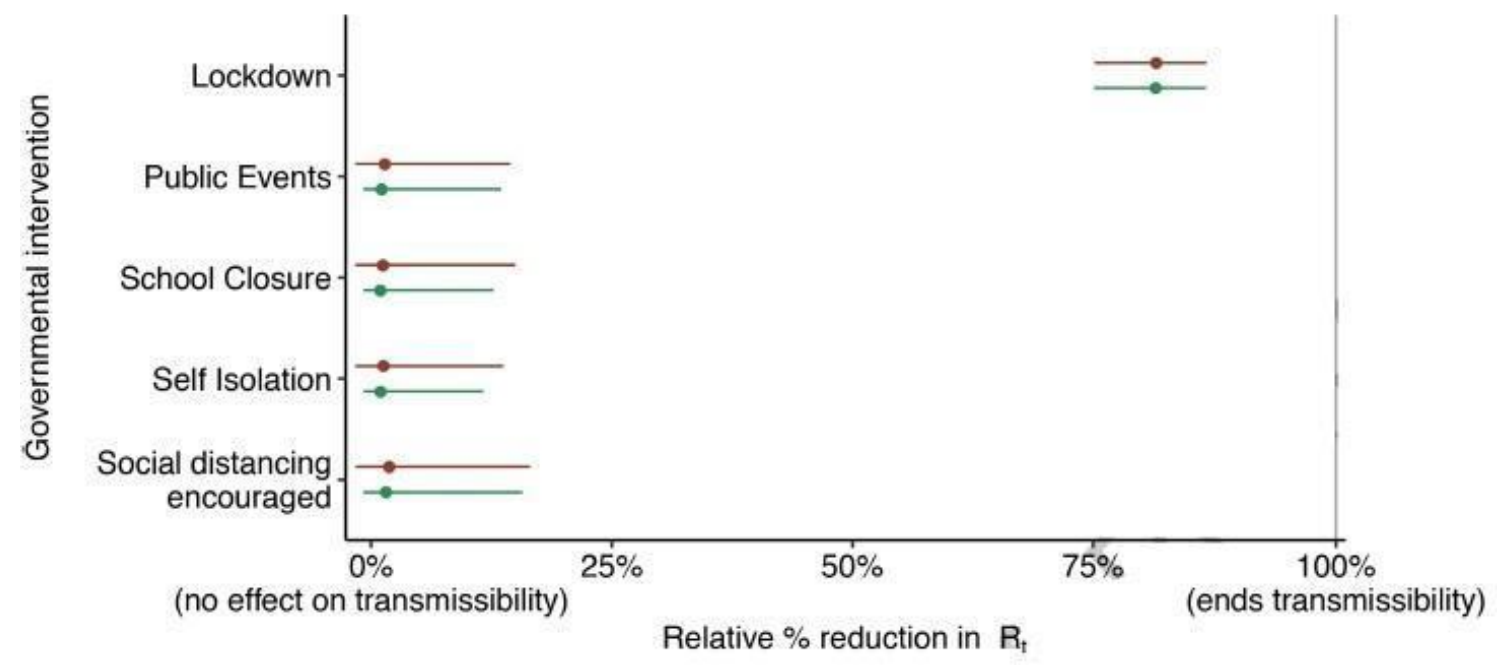

Notas: Estimación en base a 14 países europeos. Los puntos representan los valores de estimación media del impacto y las líneas el intervalo de confianza del 95\%. Este gráfico nos dice que solo las cuarentenas (lockdown) tuvieron un impacto significativo en la reducción de $R t$, mientras que el resto de las medidas tuvieron impactos más moderados o nulos dependiendo el país. Fuente: Flaxman et al. (2020) 
Tabla A1: Tabla de Hospitalización y Mortalidad utilizada por Ferguson et al (2020)

\begin{tabular}{|l|c|c|c|}
\hline $\begin{array}{l}\text { Age-group } \\
\text { (years) }\end{array}$ & $\begin{array}{c}\text { \% symptomatic cases } \\
\text { requiring hospitalisation }\end{array}$ & $\begin{array}{c}\text { \% hospitalised cases } \\
\text { requiring critical care }\end{array}$ & Infection Fatality Ratio \\
\hline 0 to 9 & $0.1 \%$ & $5.0 \%$ & $0.002 \%$ \\
\hline 10 to 19 & $0.3 \%$ & $5.0 \%$ & $0.006 \%$ \\
\hline 20 to 29 & $1.2 \%$ & $5.0 \%$ & $0.03 \%$ \\
\hline 30 to 39 & $3.2 \%$ & $5.0 \%$ & $0.08 \%$ \\
\hline 40 to 49 & $4.9 \%$ & $6.3 \%$ & $0.15 \%$ \\
\hline 50 to 59 & $10.2 \%$ & $12.2 \%$ & $0.60 \%$ \\
\hline 60 to 69 & $16.6 \%$ & $27.4 \%$ & $2.2 \%$ \\
\hline 70 to 79 & $24.3 \%$ & $43.2 \%$ & $5.1 \%$ \\
\hline $80+$ & $27.3 \%$ & $70.9 \%$ & $9.3 \%$ \\
\hline
\end{tabular}

Fuente: Ferguson et al. (2020)

Tabla A2: Parametrización del Modelo SEIR para la Ciudad Autónoma de Bs As (CABA)

\begin{tabular}{|c|c|c|c|}
\hline \multicolumn{4}{|c|}{ " Parámetros Modelo SEIR CABA } \\
\hline Población total & $2,890,151$ & $\begin{array}{c}\text { Intervención } 1 \\
(21-\text { Mar a } 21-\text { May })\end{array}$ & $50 \%$ \\
\hline Distribución etaria & CABA (censo) & $\begin{array}{c}\text { Intervención } 2 \\
\text { (22-May a } 12-J u l)\end{array}$ & $35 \%$ \\
\hline $\begin{array}{l}\text { Número de contagios } \\
\text { inicial }\end{array}$ & 100 & Días de incubación & 5 \\
\hline $\begin{array}{l}\text { Casos Importados por } \\
\text { día }\end{array}$ & 3 & Días de duración de infección & 4 \\
\hline Período Simulado & 13-Mar a 12-Jul & Días de hospitalización & 8 \\
\hline Factor Reproductivo $R_{0}$ & 2.1 & Días en UTI & 8 \\
\hline
\end{tabular}

Fuente: elaboración propia. 